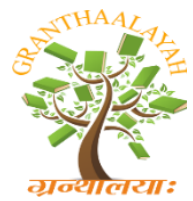

\author{
INTERNATIONAL JOURNAL OF RESEARCH - \\ GRANTHAALAYAH \\ A knowledge Repository
}

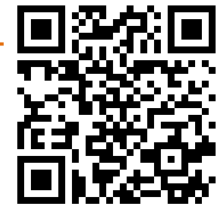

Science

\title{
COMPARISON BETWEEN RECTAL AND BODY SURFACE TEMPERATURES OBTAINED BY DIGITAL AND NON-CONTACT INFRARED THERMOMETER IN SOME LARGE ANIMAL SPECIES
}

\author{
Mera Usman Muhammed ${ }^{1}$, Mayaki Abubakar Musa ${ }^{1}$, Gambo Abdulrahman Abdullahi ${ }^{1}$ \\ ${ }^{1}$ Department of Veterinary Medicine, Faculty of Veterinary Medicine, Usmanu Danfodiyo \\ University, Sokoto, Nigeria
}

\begin{abstract}
This study was carried out to compare the digital rectal (DR) thermometer with non-contact infrared thermometer (IRT) measurements at two locations on the face in some large animal species. Two hundred and forty (240) animals comprising of equal numbers of three species (cattle, camel and horses) of varying age and either sex was used. The IR temperature was taken from two sites [frontal (FIRT) and temporal (TIRT) region] on the animal face. The mean IR temperatures (FIRT and TIRT) were higher than the RT in all the animal species. The two thermometers correlate poorly in all the animal species. Bland-Altman analysis showed high biases and limits of agreement not acceptable for clinical purposes. In conclusion, IRT seems to offer a quick and easy way to determine the animal temperature but clinically it cannot be used interchangeably with DR thermometer at the moment for body temperature measurement in these animal species.
\end{abstract}

Keywords: Digital Rectal Thermometer; Non-Contact Infrared Thermometer; Large Animal Species.

Cite This Article: Mera Usman Muhammed, Mayaki Abubakar Musa, and Gambo Abdulrahman Abdullahi. (2019). "COMPARISON BETWEEN RECTAL AND BODY SURFACE TEMPERATURES OBTAINED BY DIGITAL AND NON-CONTACT INFRARED THERMOMETER IN SOME LARGE ANIMAL SPECIES.” International Journal of Research - Granthaalayah, 7(8), 62-68. https://doi.org/10.29121/granthaalayah.v7.i8.2019.639.

\section{Introduction}

Temperature is an important indicator for diagnosis of many animal diseases and also for estimation of their physiological status. More so keeping animal healthy is not only important for high profit and performance but also for animal welfare. Thus, monitoring of animal body temperature remains an issue of necessity. The body temperature is the measurement of deep body sites or the hypothalamus (Goodwin, 1998), however, its measurement depends on the type of thermometer and the area to be taken for measurement (Rubia-Rubia et al., 2011). There are several types of clinical thermometers used in measuring body temperature: non-contact noninvasive, mildly-invasive contact, and invasive contact devices. However, an ideal temperature 
measurement technique should be safe, easy to perform, non-invasive, time efficient, should accurately reflect the core body temperature and should not be influenced by external factors (Patel et al., 2016).

Rectal temperature (RT) has been widely considered the standard method for body temperature measurement in Veterinary Medicine, because it correlates well with the core body temperature (Goodwin, 1998, Chung et al., 2010). The mercury rectal thermometry is considered the most precise, although one have to wait for about two minutes to obtain reliable RT, which is impracticable in face of a large number of animals. In case of digital rectal thermometry, RT can be gotten more quickly, about 30s, but it can serves as fomite and injuries can also occur. Rectal thermometry (RTM) is therefore considered slower, minimally invasive and associated with the risk of transmission of microorganisms and rectal perforation in agitated and indocile animals. In order to overcome the short fall of RTM, the use of infrared (IR) thermometry, a non-contact, noninvasive method which offer several advantages over other temperature measurement methods is now becoming popular in Veterinary Medicine. The principal advantages are the speed of measurement (about 2sec), non-invasive method and reduce risk of spreading infection, since touching the animal is unnecessary. In veterinary medicine, this is advantageous over other methods since handling and restraint increases stress, causing an effect on core and surface temperatures (Chung et al., 2010, Wiedemann et al., 2006).

In IR thermometry a sensor probe measures the amount of thermal radiation (ie infrared) emitted from the determined area of the body surface. It has been used to predict changes in udder temperature and to elucidate possibilities for early diagnosis of mastitis in dairy cows (Berry et al., 2003); early detection of foot-and-mouth disease virus infected cattle (Rainwater-Lovett et al., 2009); and early diagnosis of laminitis, in particular in earlier stage of lactation; screening cattle for feed utilization efficiency (Montanholi et al, 2010) and for measuring stress in studies of animal welfare. Considering the stress of manual restrain on large animal and wrong measurement due to improper positioning of the thermometer in agitated animal, and presence of feaces in the rectum, which could all affect diagnosis and therapeutic strategy, identifying an alternative way to check temperature in large animal would improve the welfare of animal and promote better veterinary practices. We therefore aim to compare the RT with non-contact infrared thermometer (IRT) measurements on the body surface in some large animal species.

\section{Materials and Methods}

\section{Study Animals}

Two hundred and forty (240) large animals comprising of three species (cattle, camel and horses) 80 each of varying age and either sex were used in this study. The animals enrolled in the study were either from Kara market and abattoir in case of cattle and camels while horses were from stables within Sokoto metropolis. All animals were determined to be healthy based on physical examination and the study was conducted in accordance with guidelines outlined in the National Institutes of Health Guide for the Care and Use of Laboratory Animals.

\section{Temperature Measurements}

RT was taken using digital rectal (DR) thermometer (Digital soft Tip; CVS, Woonsocket, rhode Island, USA) while the body surface temperatures were taken using IRT (HF-FO3B Quick shot infrared thermometer; SHENZEN TGSE electronic co ltd, Germany). The IRT was first used to 
measure the body surface temperatures of two locations of each animal before rectal temperatures were taken. The two surface locations were frontal and temporal region of the face. After positioning the IRT to the targeted area about ten centimeters from the animals head, the activation push-button was pressed and the thermometer provided readings within seconds. The IR temperatures were taken twice to ensure repeatability. The RT was taken using digital rectal thermometer after the animal has been properly restrained. The digital thermometer was inserted into the rectum, where it remained until an endpoint reading audible beep was heard. Prior to the study, accuracy of both RT was validated in a temperature controlled water bath against a reference thermometer. A temperature controlled thermal plate was used to validate the IRT. Three temperatures were obtained by the same experienced observer in the following order: forehead infrared temperature (FIRT), temporal infrared temperature (TIRT) and RT.

\section{Statistical Analyses}

Data were presented as mean, standard deviation (SD), and temperature range. Relationship between the temperature data recorded by IRT and DR thermometer was evaluated using Pearson correlation. The mean differences of temperature (bias) and 95\% agreement limits were determined as described by Bland and Altman (1986). The limits of agreement represent the range of values in which agreement between the two methods lie for $95 \%$ of the sample. The narrower the range between the two limits, the better the agreement between the two methods. The predetermined criterion for the calculated limits of agreement (mean $\pm 1.96 \mathrm{SD}$ ) between RTM and IR thermometry in the current study was $\pm 0.83{ }^{\circ} \mathrm{C}$. Therefore a difference of more than 0.83 ${ }^{\circ} \mathrm{C}$, on average, between thermometers would be clinically unacceptable (Quimby et al., 2009). Statistical analysis was conducted using GraphPad Prism 5.

\section{Results}

The mean, standard deviation (SD), temperature range, correlations and level of significance (P) of RT, FIRT and TIRT of cattle are shown in table 1 . The mean RT was $38.2^{\circ} \mathrm{C}$ while the mean FIRT and TIRT were $38.7^{\circ} \mathrm{C}$ and $38.6^{\circ} \mathrm{C}$ respectively. The maximum temperatures documented for cattle were $40.1^{\circ} \mathrm{C}$ (RT), $41.6^{\circ} \mathrm{C}$ (FIRT) and $40.2^{\circ} \mathrm{C}$ (TIRT), while the minimum temperatures recorded for IRTs were lower than RTs. The IRTs were statistically insignificant and they correlated poorly with RT.

Table 1: Mean, Standard deviation (SD), temperature range, correlations and level of significance (P) of RT, FIRT and TIRT of cattle

\begin{tabular}{|l|c|c|c|c|}
\hline Mean \pm SD $\left({ }^{\mathbf{0}} \mathbf{C}\right)$ & Range $\left({ }^{\mathbf{0}} \mathbf{C}\right)$ & \multicolumn{3}{|c|}{ Correlations (P) } \\
\hline & & RT & FIRT & TIRT \\
\hline RT 37.1 \pm 0.91 & $35.8-40.0$ & - & $0.535(0.000)$ & $0.408(0.000)$ \\
\hline FIRT 37.4 \pm 1.13 & $36.3-41.5$ & & - & 0.662 \\
\hline TIRT 37.7 \pm 0.97 & $35.2-40.1$ & & & - \\
\hline
\end{tabular}

Correlations is significance at the level of 0.01

In the horses, the correlation between RT and the IRTs were also weak (table 2), although, significant difference was observed between RT and FIRT. The mean temperature measured were $37.4^{\circ} \mathrm{C}(\mathrm{RT}), 37.6^{\circ} \mathrm{C}(\mathrm{FIRT})$ and $37.8^{\circ} \mathrm{C}(\mathrm{TIRT})$ while maximum temperatures documented for 
RT, FIRT and TIRT were $38.5^{\circ} \mathrm{C}, 38.0^{\circ} \mathrm{C}$ and $39.4^{\circ} \mathrm{C}$ respectively. The minimum temperatures recorded for FIRT and RT are the same, however, TIRT was lower.

Table 2: Mean, Standard deviation (SD), temperature range, correlations and level of significance $(\mathrm{P})$ of RT, FIRT and TIRT of horses

\begin{tabular}{|l|c|c|c|c|}
\hline Mean \pm SD $\left({ }^{\mathbf{0}} \mathbf{C}\right)$ & Range $\left({ }^{\mathbf{0}} \mathbf{C}\right)$ & \multicolumn{3}{|c|}{ Correlations (P) } \\
\hline & & RT & FIRT & TIRT \\
\hline RT 37.4 \pm 0.46 & $36.9-38.5$ & - & $0.406(0.000)$ & $0.212(0.059)$ \\
\hline FIRT 37.6 \pm 0.52 & $36.9-38.0$ & & - & 0.330 \\
\hline TIRT 37.8 \pm 0.50 & $36.7-39.4$ & & & - \\
\hline
\end{tabular}

Correlations is significance at the level of 0.01

Analysis of camel's data revealed statistically significant difference between the RT and IRTs. However, the correlation was not particularly strong (table 3). The mean RT, FIRT and TIRT were $37.1^{\circ} \mathrm{C}, 37.4^{\circ} \mathrm{C}$ and $37.7^{\circ} \mathrm{C}$ respectively. The maximum temperatures recorded were $40.0^{\circ} \mathrm{C}(\mathrm{RT})$, $41.5^{\circ} \mathrm{C}$ (FIRT) and TIRT and $40.1^{\circ} \mathrm{C}$ (TIRT). The minimal temperature was higher for FIRT and lower for TIRT when compared with RT.

Table 3: Mean, Standard deviation (SD), temperature range, correlations and level of significance $(\mathrm{P})$ of RT, FIRT and TIRT of camels

\begin{tabular}{|l|c|c|c|c|}
\hline Mean \pm SD $\left({ }^{\mathbf{0}} \mathbf{C}\right)$ & Range $\left({ }^{\mathbf{0}} \mathbf{C}\right)$ & \multicolumn{3}{|c|}{ Correlations (P) } \\
\hline & & RT & FIRT & TIRT \\
\hline RT 37.1 \pm 0.91 & $35.8-40.0$ & - & $0.535(0.000)$ & $0.408(0.000)$ \\
\hline FIRT 37.4 \pm 1.13 & $36.3-41.5$ & & - & 0.662 \\
\hline TIRT 37.7 \pm 0.97 & $35.2-40.1$ & & & - \\
\hline
\end{tabular}

Correlations is significance at the level of 0.01

Bland-Altman analysis of the temperatures obtained by using the two thermometry methods (Table 4) revealed disagreement between RT and those from IRTs. In horses where the mean difference (bias) appeared smaller for FIRT when compare with other animal species. The range of the limits of agreement is around $2^{\circ} \mathrm{C}$ which is too wide to be clinically acceptable. Also for cattle and camels, the IRT showed even greater biases, and failed to agree with rectal readings. The range of the limits of agreement for FIRT and TIRT in camels were around $3^{\circ} \mathrm{C}$ respectively while in cattle is around $5^{\circ} \mathrm{C}$ for FIRT and $4^{\circ} \mathrm{C}$ for TIRT.

Table 4: Bias and limits of agreement $\left({ }^{\circ} \mathrm{C}\right)$ between temperatures measured by rectal and infrared thermometers in cattle, horses and camels

\begin{tabular}{|l|l|c|c|c|}
\hline Animal species & Type of measurement & Bias & SD & 95\% limits of agreement \\
\hline Cattle & RT minus FIRT & -0.4253 & 1.3075 & $-2.9881,2.1374$ \\
\hline & RT minus TIRT & -0.3813 & 1.1375 & $-2.6108,1.8483$ \\
\hline Horses & RT minus FIRT & -0.1900 & 0.5369 & $-1.2423,0.8623$ \\
\hline & RT minus TIRT & -0.4163 & 0.6064 & $-1.6048,0.7723$ \\
\hline Camels & RT minus FIRT & -0.3846 & 0.9884 & $-2.3219,1.5526$ \\
\hline & RT minus TIRT & -0.5425 & 1.0260 & $-2.5534,1.4684$ \\
\hline
\end{tabular}




\section{Discussion}

The use of IRT in this present study allowed us to assess its usefulness and practicality in clinical setting, since most large animal cases are handled in the field with sometime minimal restraining facilities. The possibility of cross infections and restraint induced rectal injuries associated with rectal temperature measurements also necessitate the need for alternative methods to temperature measurement in animals, particularly large animal species where the individual to take the temperature is at risk of injury from hind-limb kicks. Noncontact noninvasive thermometry alternative methods to rectal temperature measurement have been investigated in different animal species. It reliability in human medicine has been documented (Osio and Carnelli, 2007), however, studies in veterinary medicine showed varying results among different species of animals. This does not mean that temperatures from IR thermometry are inaccurate for veterinary use. It is crucial to note that body temperature varies by location (Nobel, 1992), and since the IRTs used in most of those studies do not measured temperature at the same location, variation in reading is expected. Most of the studies in different animal species used infrared auricular thermometers (Drew 1996, Goodwin, 1998, Southward et al., 2006, Sousa et al., 2011, Sousa et al., 2013). Although the use of noncontact infrared technology at other locations has also been reported (Devalle, 2005, Shelton et al., 2006, Sikoski et al., 2007, Ramey et al., 2011, Brunell, 2012).

This is the first study to the best of our knowledge that investigated the use of an IRT in cattle, horses and camel to measure body temperature. In this present study we used IRT designed for humans because it is widely available than veterinary IRTs. And the two sites chose on the face of the animals for the IR temperatures were also considered because the IRT used measured temperature on the forehead in the human (Fortuna et al., 2010; Teran et al., 2012). The temperatures measured at the frontal and temporal region of the face of the animals studied were not in close agreement with the RT, therefore cannot be used interchangeably, although the mean differences (biases) between temperature measurements were small. The mean IR temperatures were higher than the RT in all the animal species studied. Higher IR temperature was documented by Kunkle et al. (2004) in the cat, however most studies reported lower temperatures for IR when compare with RT (Wiedemann et al., 2006; Ramey et al., 2011; Brunell, 2012; Schmidt et al., 2013). The variation in sites measured and also probably the devices used may be the reasons for higher IR temperatures. It has also been documented that changes in RT may lag significantly from the temperature detected at other body sites (Fraden and Lackey, 1991). There was significant variation in IR temperature readings among the sites at which the temperature was taken when compare to the RTs particularly in horses and camels. The temperature ranges at these locations were also highly variable when compared with the RT ranges. The variation between the FIRT and RT was greater than that between the TIRT and RT in the cattle. On the contrary, in horses and camel, variation between the FIRT and RT was lesser than that between the TIRT and RT. The correlation between the RT and the IR temperatures from two the sites (FIRT and TIRT) in all the animals studied were also poor except in camel where moderate correction $(r=0.535)$ exists between the RT and FIRT. These findings of IRTs been poorly correlated with and no agreement to RT in the cattle, horses and camels were in agreement with previous studies in cat, dog, pig, horse, ponies, cattle and macaques or owl monkeys (Kunkle et al., 2004, Wiedemann et al., 2006; Shelton et al., 2006, Ramey et al., 2011, Johnson et al., 2011, Brunell, 2012, Schmidt et al., 2013). Although in all those studies sites or location different from the face were used, particularly chest (macaques), cornea (dog), tympanic membrane (cat), gingival and eyes (horse and pony) and other 
body parts (swine). We believe the bias observed between the two thermometers may represent a true physiological difference between body sites rather than inaccuracy of the IR thermometer or operator error.

\section{Conclusion}

There was poor agreement between IRT and DR thermometers measurement in the cattle, horses and camel, and the two thermometers did not correlate well. Though IRT seems to offer a quick and easy way to determine the animal temperature but clinically it cannot be used interchangeably with DR thermometer at the moment for body temperature measurement in these animal species.

\section{References}

[1] Berry, R.J., Kennedy, A.D., Scott, S.L., Kyle, B.L. and Schaefer, A.L. (2003). Daily variation in the udder surface temperature of dairy cows measured by infrared thermography: Potential for mastitis detection. Can. J. Anim. Sci. 83, 687-693.

[2] Bland, J.M. and Altman, DG. (1986). Statistical methods for assessing agreement between 2 methods of clinical measurement. Lancet 1:307-310.

[3] Brunell, M.K. (2012). Comparison of noncontact infrared thermometry and 3 commercial subcutaneous temperature transponding microchips with rectal thermometry in rhesusmacaques (Macaca mulatta). J Am Assoc Lab Anim Sci. 51(4):479-484.

[4] Chung, T-h., Jung, W-s., Nam, E-h., Kim, J-h., Park, S-h and Hwang, C-Y. (2010). Comparison of rectal and infrared thermometry for obtaining body temperature of gnotobiotic piglets in conventional portable germ free facility. Asian-Aust. J. Anim. Sci. 23(10):1364-1368.

[5] Devalle. (2005) Comparison of tympanic, transponder, and noncontact infrared laser thermometry with rectal thermometry in strain 13 guinea pigs. Contemp Topics Lab Anim Sci. 44(5):35-38.

[6] Drew, M.L. (1996). The use of a tympanic membrane thermometer for assessing hyperthermia in bighorn sheep. J Wildl Dis. 32(3):512-516.

[7] Fraden, J. and Lackey, R.P. (1991). Estimation of body sites temperatures from tympanic measurements. Clin Pediatr. 30(4):65-70.

[8] Fortuna, E.L, Carney, M.M, Macy, M, et al. (2010). Accuracy of non-contact infrared thermometry versus rectal thermometry in young children evaluated in the emergency department for fever. $J$ Emerg Nurs. 36(2):101-104.

[9] Goodwin, S. (1998). Comparison of body temperatures of goats, horses, and sheep measured with a tympanic infrared thermometer, an implantable microchip transponder, and a rectal thermometer. Contemp. Top. Lab. Anim. Sci. 37(3):51-55.

[10] Johnson, S.R., Rao, S., Hussey, S.B., Morley, P.S., Traub-Dargatz, J.L. (2011). Thermographic eye temperature as an index to body temperature in ponies. J Equine Vet Sci. 31:63-6.

[11] Kunkle, G.A., Nicklin, C.F. and Sullivan-Tamboe, D.L. (2004). Comparison of body temperature in cats using a veterinary infrared thermometer and a digital rectal thermometer. J. Am Anim Hosp Assoc. 40(1):42-46.

[12] Monthanoli, Y.R., Swanson, K.C., Palme, R., Schenkel, F.S., McBride, B.W., Lu, D. and Miller, S.P. (2010). Assessing efficiency in beef steers through feeding behaviour, infrared thermography and glucocorticoids. Animal, 4(5):692-701.

[13] Nobel, J.J. (1992) Infrared ear thermometry. Pediatr Emerg Care. 8(1):54-58.

[14] Osio, C.E. and Carnelli, V. (2007). Comparative study of body temperature measured with a noncontact infrared thermometer versus conventional devices. Minerva Pediatr. 59:327-36.

[15] Patel, A.H., Patel, M.M. and Bhavsar, R.H. (2016). Comparison of Non-Contact Forehead Infrared Thermometry with Axillary Digital Thermometry in Neonates. GCSMC J. Med. Sci. 20(1): 20-24 
[16] Quimby, J.M., Olea-Popelka, F. and Lappin, M.R. (2009). Comparison of Digital Rectal and Microchip Transponder Thermometry in Cats. Journal of the American Association for Laboratory Animal Science. 48(4): 1-4

[17] Rainwater-Lovett, K., Pacheco, J.M., Packer, C. and Rodriguez, L.L. (2009). Detection of foot-and mouth disease virus infected cattle using infrared thermography. The Veterinary Journal, 180:317324.

[18] Ramey, D., Bachmann, K. and Lee, M.L. (2011). A comparative study of noncontact infrared and digital rectal thermometer measurements of body temperature in the horse. J Eq Vet Sci 31(4):191193.

[19] Rubia-Rubia, J., Arias, A., Sierra, A, Aguirre-Jaime, A. (2011). Measurement of body temperature in adult patients: Comparative study of accuracy, reliability and validity of different devices. International Journal of Nursing Studies. 48:872-880.

[20] Schmidt, M., Lahrmann, K-H., Ammon, C., Berg, W., Schön, P. and Hoffmann, G. (2013). Assessment of body temperature in sows by two infrared thermography methods at various body surface locations. J Swine Health Prod. 21:203-9.

[21] Shelton, Jr L.J., White, C.E. and Felt, S.A. (2006). A comparison of non-contact, subcutaneous, and rectal temperatures in captive owl monkeys (Aotus sp.). J Med Primatol. 35(6):346-51.

[22] Sikoski, P., Banks, M., Gould, R., et al. (2007). Comparison of rectal and infrared thermometry for obtaining body temperature in cynomolgus macaques (Macaca fascicularis). J Med Primatol. 36(6):381-384.

[23] Southward, E., Mann, F.A, Dodam, J., et al. (2006). A comparison of auricular, rectal and pulmonary artery thermometry in dogs with anesthesia induced hypothermia. J Vet Emerg Crit Care. 16(3):172-175.

[24] Sousa, M.G., Carareto, R., Pereira-Junior, V., et al. (2011)Comparison between auricular and standard rectal thermometers for the measurement of body temperature in dogs. Can J Vet Res. 52(4):403-406.

[25] Sousa, M.G., Carareto, R., Pereira-Junior, V.A., et al. (2013). Agreement between auricular and rectal measurements of body temperature in healthy cats. J Fel Med Surg. 15(4):275-279.

[26] Teran, C.G., Torrez-Llanos, J., Teran-Miranda, T.E., et al. (2012). Clinical accuracy of a noncontact infrared skin thermometer in paediatric practice. Child Care Health Dev. 38(4):471-476.

[27] Wiedemann, G.G.S., Saclon, M.C., Paludo, G., Silva, I.O., Boere, V. (2006). Comparison between tympanic and anal temperature with a clinical infrared ray thermometer in dogs. Arq. Bras. Med. Vet. Zootec. 58: 503-505.

*Corresponding author.

E-mail address: usmanmera2@ gmail.com 